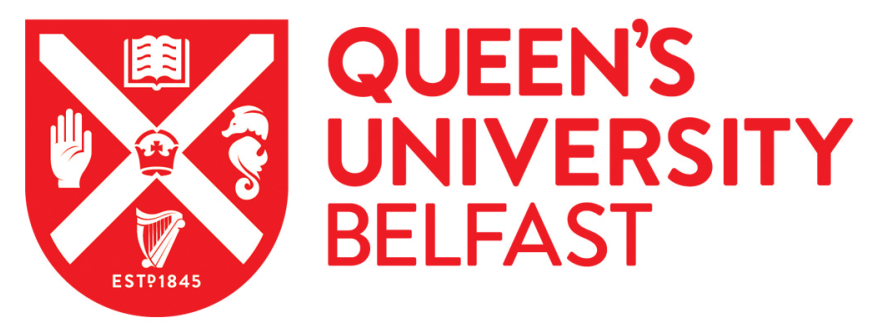

\title{
The role of the Clinical Nurse Specialist as a non-medical prescriber in managing the palliative care needs of individuals with advanced lung cancer: A United Kingdom perspective
}

Osborne, J., \& Kerr , H. (2021). The role of the Clinical Nurse Specialist as a non-medical prescriber in managing the palliative care needs of individuals with advanced lung cancer: A United Kingdom perspective. International Journal of Palliative Nursing, 27(4), 334-342. https://doi.org/10.12968/ijpn.2021.27.4.205

Published in:

International Journal of Palliative Nursing

Document Version:

Peer reviewed version

Queen's University Belfast - Research Portal:

Link to publication record in Queen's University Belfast Research Portal

\footnotetext{
Publisher rights

Copyright 2020 Mark Allen Healthcare. This work is made available online in accordance with the publisher's policies. Please refer to any applicable terms of use of the publisher.
}

\section{General rights}

Copyright for the publications made accessible via the Queen's University Belfast Research Portal is retained by the author(s) and / or other copyright owners and it is a condition of accessing these publications that users recognise and abide by the legal requirements associated with these rights.

\section{Take down policy}

The Research Portal is Queen's institutional repository that provides access to Queen's research output. Every effort has been made to ensure that content in the Research Portal does not infringe any person's rights, or applicable UK laws. If you discover content in the Research Portal that you believe breaches copyright or violates any law, please contact openaccess@qub.ac.uk. 
Title:

The role of the clinical nurse specialist as a non-medical prescriber in managing the palliative care needs of individuals with advanced lung cancer: A United Kingdom perspective.

\section{$\underline{\text { Keywords }}$}

Non-medical prescriber

Advanced Lung Cancer

\section{$\underline{\text { Reflective questions }}$}

1. Is the Clinical Nurse Specialist in an ideal position to independently prescribe medications?

2. What are the challenges for Clinical Nurse Specialist in independently prescribing medications?

3. How are patient outcomes improved from independent non-medical prescribing for individuals with advanced lung cancer?

\section{Journal}

International Journal of Palliative Nursing 


\section{$\underline{\text { Introduction }}$}

This paper focuses on the role of the Clinical Nurse Specialist as an independent non-medical prescriber in managing the palliative care needs of individuals with advanced lung cancer. The background to the introduction of non-medical prescribing in the United Kingdom (UK) will be provided and a discussion on the benefits and barriers of this role in the context of advanced lung cancer with a focus on patient outcomes. The Clinical Nurse Specialist role has already demonstrated benefits to both patients and organisations, with reduced delays in patients receiving medication, less hospital appointments and admissions, and improved patient outcomes (Dowden 2016). With continuous professional development and upskilling, and the increasing autonomous nature of the Clinical Nurse Specialist role, they are ideally placed to practice at an advanced level in the role as a non-medical prescriber. As the nursing profession progresses into the third decade of this millennium, the rhetoric will highlight that non-medical prescribing is an intervention that can improve patient outcomes for individuals with advanced lung cancer in a timely manner and should be precipitously adopted universally by the Clinical Nurse Specialist.

\section{Lung cancer}

Globally, lung cancer is one of the most frequently occurring malignancies with a five-year survival rate lower than that of other leading cancers (Wong et al, 2017). It imposes a significant disease burden as it has the highest fatality rate among all cancers (Cheng et al, 2016). In the UK with an approximate overall population of 66 million, it is reported there around 47,200 new lung cancer diagnoses every year, with more than two thirds of individuals diagnosed at an advanced stage, and accounts for around 35,300 deaths every year (Cancer Research UK, 2017). Although there have been significant improvements in treatment 
options for individuals with advanced lung cancer, a late diagnosis could result in rapid disease progression and increasing symptom burden, with greater psychological health challenges (Ngwenya et al, 2015). Treatment for individuals with non-curative, advanced metastatic lung cancer, can be a combination of palliative systemic or oral therapies, radiotherapy and best supportive care to improve or stabilise the wellbeing of individual patients, with patients too unwell to undergo palliative treatment interventions, being offered supportive care alone (Li and Li, 2016). Early identification of the palliative care needs of individuals with advanced lung cancer is imperative in contributing to a holistic approach aimed at maximising the patients' quality of life and the delivery of exemplary standards of patient-centred holistic care (Ahmed et al, 2004). Independent non-medical prescribing by Clinical Nurse Specialists should enhance patient outcomes for individuals with advanced lung cancer.

\section{Background to non-medical prescribing}

Cope et al (2016) describe non-medical prescribers as healthcare professionals who are not doctors or dentists who complete an advanced qualification to lawfully prescribe medicines, dressings and appliances. Globally, the UK and Ireland are considered to be at the forefront of non-medical prescribing with the most extended non-medical prescribing rights (Abuzour et al, 2018). In practice, non-medical prescribing has evolved over the years so is not a new concept. Historically, it was recognised that a significant amount of community nursing time was wasted visiting family medical practitioners to obtain prescriptions for patients (Nutall and Howard 2011). The Cumberlege Report in the UK (Department of Health and Social Security, 1986) originally proposed non-medical prescribing following the review of care given to patients by community health care professionals such as district nurses and health visitors. The report recommended that patient care could be improved, and resources used more 
efficiently and effectively if community nurses were able to prescribe certain medications such as wound dressings and ointments as part of their role, as they had already undertaken a patient assessment to identify their needs (Cope et al, 2016). The recommendations from the Cumberlege Report (Department of Health and Social Security, 1986) resulted in the publication of the first Crown Report (Department of Health 1989). This report contemplated the introduction of prescribing by professionals who were not medically qualified, one such example being community nurses, to enable them to prescribe from a limited list, or formulary, in an attempt to ensure more efficient use of nursing and medical time. However, it took three years for changes in legislation to enable community nurses to prescribe from The Extended Formulary for Nurse Prescribers (Department of Health and Social Security, 1992). Nurse prescribers criticised this formulary for being too restricted, which resulted in the progression of community nurse prescribing continuing and publication of the Crown Report II (Department of Health 1999). This report acknowledged the government's plan in the UK to train 20,000 nurses and health visitors over a two-year period to make nurse prescribing a reality. Following a period of consultation, the government extended prescribing privileges to other groups of nurses and Allied Health Professionals (Cope et al, 2016). The Nursing and Midwifery Council (NMC), the professional regulator for nurses and midwives in the UK, implemented standards in prescribing practice for nurses and midwives to ensure proficiency in skills such as assessment, diagnosis, care planning, care management and pharmacology and leadership, in the delivery of safe and effective care (NMC 2018). Public safety is further compounded by ensuring that all NMC approved programmes must deliver outcomes, which meet the Royal Pharmaceutical Society's (RPS) competency framework for all prescribers (RPS 2016). The most recent statistics indicate 
there are over 54,000 nurse and midwife prescribers throughout the UK (Royal College of Nursing 2014).

There are currently three non-medical prescribing options for nurses in the UK; community practitioner nurse prescribing; independent nurse prescribing; and nurse supplementary prescribing (Ward and Armstrong 2015). Community practitioner nurse prescribing allows community nurses to prescribe independently but from a limited formulary; independent nurse prescribers can prescribe any drug from the British National Formulary (BNF) provided they are clinically qualified to do so and within their area of competence; and finally, supplementary prescribing involves prescribing by the nurse from the BNF with a patient specific management plan agreed by a medical doctor (Dowden 2016). This paper will predominately focus on the role of the nurse as an independent nurse prescriber due to its relevance in ensuring swift management of symptoms for patients with advanced lung cancer.

\section{$\underline{\text { Role of Clinical Nurse Specialist as a non-medical prescriber }}$}

The National Cancer Action Team (National Cancer Action Team, 2010) describe the role of Clinical Nurse Specialists as clinical experts in evidenced based nursing practice within a particular speciality. They practice at an advanced level to treat and manage the health concerns of patients, and work to maximise the health and wellbeing for patients they care for (National Cancer Action Team, 2010). Their role is complex and comprises of symptom management, in addition to social, spiritual and psychological support (Latham and Nyatanga,

2018a). Timely access to medications as advocated by the National Institute of Clinical Excellence (NICE 2015) places the Clinical Nurse Specialist in an ideal position to secure optimum symptom control. Consideration of the benefits of independent nurse prescribing to ensure rapid access to medications and improvements in quality of life are essential for 
individuals who are at the terminal stage of their illness (NICE, 2015). McPhillips et al (2015) explored the role of the Clinical Nurse Specialist in a modern lung cancer service, stressing the pivotal role they play in the delivery of high quality care and treatment. The role is diverse, holistic and patient centred, and aims to fulfil the supportive and palliative care needs of patients. In patients with lung cancer, Tod et al (2015) identified that through good management of symptoms, the Clinical Nurse Specialist can assist in the optimisation of the patients' performance status to enhance their opportunity to receive active treatment. The rapid identification of symptoms by the Clinical Nurse Specialist should contribute to enhancing the individuals' quality of life, and provide timely access to medications to manage symptoms, which aims to improve patient outcomes. Although the aim of care is to review patients early in the lung cancer pathway (Roy Castle Lung Cancer Foundation 2013), patients with lung cancer are often given a life changing diagnosis with a short disease trajectory (McPhillips et al, 2015). This highlights the importance of an early assessment and identification of symptoms facilitated by the independent nurse prescriber when patients are in the terminal phase of their disease (Dawson 2013).

As the lung cancer trajectory progresses, patients' palliative care needs may change rapidly and will require meticulous monitoring of symptoms, which may include reviewing medications, especially for patients approaching the end of life. A case study carried out by Dawson (2013) described the effectiveness of independent nurse prescribing within a community palliative care team focussing on patients approaching end of life. The results suggested that patients had more timely access to medications when prescribed by the Clinical Nurse Specialist independent prescriber, than when prescribed by their General Practitioner/Family Physician. Whilst these findings suggest favourable results, this study only recruited thirty two patients in one geographical area in England, UK. Therefore, larger 
sample sizes from wider geographical areas should be undertaken to establish if independent nurse prescribing leads to earlier access to medications in patients in specific populations such as advanced lung cancer. This study does, however, identify how nurses prescribing can be invaluable in responding to patient need in a timely manner (Creedon and O'Regan, 2013). It is for this reason that patients with advanced lung cancer experiencing complex palliative care needs should have swift access to the medications required to ensure their symptoms are managed effectively (NICE 2015).

Benefits of the Clinical Nurse Specialist in the role of Independent Nurse Prescriber for individuals with advanced lung cancer

There are a number of benefits related to the Clinical Nurse Specialist as independent Nurse Prescriber (Table one).

Rapid assessment and management of physical and psychological symptoms

At the time of diagnosis, patients with lung cancer may be relatively asymptomatic of their disease, however, the evolution of lung cancer is usually marked by symptoms that are likely to significantly impact on their quality of life (Lafitte et al, 2018). Patients with advanced disease face a shortened life expectancy, that can become progressively more symptomatic, highlighting the importance of early recognition and management of physical symptoms (Yount et al, 2012). One of the potential benefits of independent nurse prescribing for individuals with advanced lung cancer is related to the prompt assessment and management of distressing symptoms such as dyspnoea and pain (Lafitte et al, 2018). Independent nurse prescribers can lawfully prescribe controlled drugs such as morphine sulphate (Griffith and Tengnah, 2011), therefore, contributing to the prompt intervention in the management of symptoms. Swift recognition and handling of troublesome symptoms could also contribute 
to a reduction in the levels of anxiety and distress and improve the quality of life in patients with advanced lung cancer approaching the end of their disease trajectory (Nunn, 2014). Mula and Ware (2003) also identify the importance of early recognition and response to patient needs, therefore, promoting a streamlined service that reduces patient and carer distress. However, to achieve this, an accurate assessment and diagnosis is crucial, involving complex decision making which may generate anxiety in an inexperienced nurse prescriber (Mula and Ware 2003).

\section{Improving clinical outcomes}

Actively improving clinical outcomes for the patient is paramount and can be facilitated by the Clinical Nurse Specialist due to their enhanced education and training (Ward 2018). In a randomised controlled trial (Temel et al, 2010) it was identified that patients with stage four metastatic non-small cell lung cancer who received early palliative care had significant improvements in their quality of life and mood compared to patients receiving standard oncological care. In addition, survival was prolonged by approximately 2 months, highlighting the significance of early interventions for quality of quantity of life.

A study by Latham and Nyatanga (2018b) outlined five advantages perceived by community palliative care Clinical Nurse Specialists who were independent prescribers. Results found that helping patients in a time of crisis, being available when others are not, gaining satisfaction from being able to provide holistic care, knowledge to prescribe the right medicines at the right time, and increased knowledge of pharmacology were important factors in ensuring effective symptom control. The viewpoints identified by the Clinical Nurse Specialists highlight the importance of timely access to medicines for individuals 
approaching the end of their lives, as emphasised by NICE (2015) to improve their quality of life (Latham and Nyatanga 2018b).

\section{Multidisciplinary support}

Multidisciplinary team support is essential to promote confidence in practitioners in patient assessment as part of their prescribing practice (Lewis-Evans and Jester 2004). There are several ways in which this can be achieved. Bradley and Riley (2013) suggest that regular supervision between non-medical prescribers and medical mentors provide collaborative working, and a platform on which to base discussion about prescribing scenarios. Likewise, the competency framework for all prescribers (Royal Pharmaceutical Society 2016) advocates multidisciplinary working to encourage support and supervision whilst respecting all practitioners' roles in relation to prescribing. With good multidisciplinary working, continuity of care can be developed and maintained across care settings (RPS, 2016).

Challenges and Barriers to the Clinical Nurse Specialist in the role of Independent Nurse Prescriber for individuals with advanced lung cancer

Whilst perceived benefits by independent nurse prescribers are well documented, there are also challenges and potential barriers to this role (Table two).

Reluctance of the practitioner to be a non-medical prescriber and inadequate medical mentoring

One barrier associated with independent nurse prescribing relates to a reluctance and lack of motivation of the practitioner to be a non-medical prescriber. A national survey reported by Ryan-Woolley et al (2007) found a lack of enthusiasm among specialist nurses in cancer and palliative care in undertaking the role of nurse prescriber. Concerns were expressed 
about the length, depth and specificity of their training. In addition to this, there was apprehension reported related to inadequate medical mentoring. As this study was completed almost 13 years ago, an updated study would determine if attitudes have changed as there has been significant work undertaken over the previous decade to promote the role of non-medical prescribing for nurses.

\section{Frustration of medical colleagues}

Using a survey questionnaire comparing doctors and nurses prescribing habits, Funnell et al (2014) found that doctors felt frustrated at the slow development of nurses when prescribing, believing they were unnecessarily cautious. However, it was recognised by the doctors in this study that independent nurse prescribers elicited greater patient concordance and identification of their prescribing needs. Additionally, it was felt that nurses showed a better holistic understanding of patients, understanding the context and situation in which they were prescribing more than their medical counterparts, whilst doctors centred more on their physiological understanding and confidence in prescribing. Findings from this survey identified the positive gain in independent nurse prescribing, however, it also indicated there is a reluctance for nurses to prescribe. One recommendation from these findings is the inclusion of nurse prescribers within teams, as proposed in their competency framework for all prescribers by The Royal Pharmaceutical Society (2016), advocating peer support from other prescribers. This could allow nurse prescribers to critique and evaluate their practice and to help alleviate anxieties associated with their prescribing practice. Organisations should, therefore, provide protected formal supervision in order to ensure a greater focus on the benefits of independent prescribing by clinical nurse specialists in delivering high quality, patient centred care (Bradley and Nolan, 2007; Carey and Stenner 2011). 
Anxiety, knowledge and lack of confidence in writing prescriptions

Further perceived barriers for non-medical prescribers relates to anxiety associated with writing prescriptions incorrectly, concerns about inadequate knowledge, negative or unfavourable attitudes of other healthcare professionals and the inability to access patients notes (Ryan-Wooley et al, 2007). In a regional survey of non-medical prescribing in palliative care, similar concerns were raised by Clinical Nurse Specialists caring for individuals who had palliative care needs (Ziegler et al (2015) related to a lack of confidence and fear of making prescribing errors. In order to for CNS's to practice with increased confidence, independent nurse prescribers should have continuous access to support and supervision of their nonmedical prescriber peers and the multidisciplinary team (Bradley and Riley 2013).

Lack of medical, peer and management support

Clinical Nurse Specialists involved in non-medical prescribing in a palliative care context, reported a lack of General Practitioner/Family Physician support, and also peer and management support (Ziegler et al. 2015). In order to improve outcomes for patients with advanced lung cancer approaching end of life, additional support and mentoring may help alleviate some of the anxieties previously outlined experienced by independent nurse prescribers. Furthermore, a shared vision between government, professional regulators, policy and healthcare managers is essential to overcome these barriers to ensure the best outcomes for patients (Noblet et al, 2017).

\section{$\underline{\text { Review of the Role in Practice }}$}

The Clinical Nurse Specialist plays a crucial role in the delivery of patient centred, holistic care for patients with lung cancer (Roy Castle Lung Cancer Foundation 2013). Creedon and 
O'Regan (2013) suggest that one of the key factors in the success of independent nurse prescribing is the nurse-patient relationship. The continuity of care provided by the independent nurse prescriber has a beneficial effect, which can enhance patient satisfaction. A literature review reported by Creedon and O'Regan (2013), suggested that patients viewed independent nurse prescribing positively in terms of convenience, accessibility and safety, however, Banicek (2012) and MacLure et al (2013) identified some apprehension related to the nurse prescribers' qualifications and knowledge. Experience and knowledge are essential components in enhancing patient confidence and satisfaction in the independent nurse prescriber. In specialised areas such as palliative care, clinical experience is essential. A qualitative study explored the experiences of six community palliative care Clinical Nurses Specialists who had completed a non-medical prescribing course (Latham and Nyatanga, 2018a). It was identified that each nurse had a minimum of six years working in palliative care, highlighting the considerable knowledge, skills and expertise of these nurses. In a questionnaire survey conducted by Courtenay et al (2012), it was recognised that non-medical prescribers with greater experience were more likely to make use of their prescribing qualification than those with less experience. Similarly, those who had completed a specialist practice qualification, approved by the NMC, reported that their enhanced knowledge had prepared them to prescribe with more confidence, whilst those who had not completed a specialist practice qualification, felt less certain when prescribing. It is apparent that experience enhances confidence and helps to maximise the favourable utilisation of the non-medical prescribing role (Courtenay et al, 2012).

Whilst evidence demonstrates the benefits of independent nurse prescribing by the Clinical Nurse Specialist (Kinley et al, 2004; Creedon and O'Regan 2013; Carey and Stenner 2011), the development of this role has been met with considerable challenges in terms of concerns 
related to the adequacy of training by nurses to diagnose medical conditions (Ryan-Wooley et al, 2007). Whilst these views are valid, a national shortage of doctors means that appropriately educated and trained Clinical Nurse Specialists can supplement services and resource management by independently prescribing within their area of expertise in an attempt to relieve some of the burden upon their medical colleagues (Funnel et al, 2014). With the predicted short disease trajectory with an advanced lung cancer diagnosis, this could be viewed as an important, patient-centred approach aimed at maximising resources and ensuring the delivery of effective quality patient care (Carey and Stenner 2011).

\section{Conclusion}

With the move into the third decade of this millennium, it is argued that the delivery of a modern lung cancer service depends on the Clinical Nurse Specialist playing a fundamental role in the overall lung cancer pathway (McPhillips et al, 2015). Individuals with advanced lung cancer are likely to have complex palliative care symptoms, especially when they are approaching the end of their disease trajectory. Reports of positive outcomes related to the role of the Clinical Nurse Specialist as a non-medical prescriber for the individual with advanced lung cancer, places this role in an ideal position to optimise and manage distressing symptoms and maximise performance status in order to improve access to palliative interventions. The role of the Clinical Nurse Specialist as an independent nurse prescriber is pivotal in the early access to medications as recommended by NICE (2015) in managing these symptoms. The benefits include the swift management of complex symptoms to maximise the patients' quality of life, promoting comfort and dignity in end of life care. Experienced, confident nurses are essential in enhancing patient confidence and the delivery of safe and effective high quality, person-centred care. However, there are many factors, 
which may influence nurse prescribing such as fear of prescribing errors, inadequate knowledge and negative attitudes of other health care professionals (Latham and Nyatanga 2018b). The role of the independent nurse prescriber continues to be an exciting initiative in the delivery of high quality, holistic person-centred care, however, a lack of engagement by the Clinical Nurse Specialist to participate in training due to concerns regarding the increased accountability, inadequate mentoring and increased workload may be some of the factors contributing to an individual's choice not to engage in education programmes to independently prescribe. To incentivise this role for Clinical Nurse Specialists providing care to patients with advanced lung cancer, protected time for continuing professional development, with mentorship and peer support is essential to support independent nurse prescribers to further develop confidence and competence and encourage reluctant others to consider this as a viable pathway in expanding their practice and improving patient outcomes. 
References

Abuzour AS, Lewis PJ, and Tully MP. Practice makes perfect: A systematic review of the expertise development of pharmacist and nurse independent prescribers in the United Kingdom. Research in Social and Administrative Pharmacy. 2018; 14(1): 6-17.

Ahmed N, Ahmedzai SH, Vora V, Harrison S, Paz S. Supportive care for patients with gastrointestinal cancer, Cochrane Database of Systematic Reviews. 2004; 3, pp.1-30.

Banicek J. Attitudes of postoperative patients towards hospital nurse prescribing. Nurse Prescribing. 2012; 10(12): 612-618.

Bradley E, Riley C. Module 20. Continuing professional development: The role of nurse prescribers in the multidisciplinary team. Nurse Prescribing. 2013;11(3):1-6.

Bradley E, Nolan, P. Impact of nurse prescribing: a qualitative study. Journal of Advanced Nursing. 2007; 50(2): 120-128.

Cancer Research UK (CRUK). Lung cancer statistics. 2017. [cited 2019 Nov 9]. Available from https://www.cancerresearchuk.org/health-professional/cancer-statistics/statisticsby-cancer-type/lung-cancer (accessed 30 December 2019)

Carey N, Stenner K. Does non-medical prescribing make a difference to patients? Nursing Times, 2011; 107(26): 14-16.

Cheng TD, Cramb SM, Baade PD, Youlden DR, Nwogu C, Reid ME. The international epidemiology of lung cancer: Latest trends, disparities and tumor characteristics. Journal of Thoracic Oncology.2016; 11(10): 1653-1671. 
Cope LC, Abuzour AS, Tully, MP. Nonmedical prescribing: where are we now? Therapeutic Advances in Drug Safety. 2016; 7(4): 165-172.

Courtenay M, Carey N, Stenner K. An overview of non medical prescribing across one strategic health authority: a questionnaire survey. BMC Health Services Research. 2012; 12(138): 1-13.

Creedon R, O'Regan P. Palliative care, pain control and nurse prescribing. Nurse Prescribing. 2013; 8(6): 257-264.

Dawson S. Evaluation of nurse prescribing in a community palliative care team. Nurse Prescribing. 2013; 11(5): 246-249.

Department of Health. Report of the Advisory Group on Nurse Prescribing (The Crown Report). London: The Stationery Office; 1989.

Department of Health. Review of Prescribing, Supply and Administration of Medicines: Final Report (The Crown Report II). London: The Stationery Office; 1999.

Department of Health and Social Security (DHSS). Neighbourhood Nursing- a focus for care. Report of the community nursing review Cumberlege Report. London: HMSO; 1986.

Department of Health and Social Security (DHSS). Medicinal Products; Prescriptions by Nurses etc. Act. London: HMSO; 1992.

Dowden A. The expanding role of nurse prescribers. Prescriber. 2016; 27(6): 24-27.

Funnell F, Minns K, Reeves K. Comparing nurses' and doctors' prescribing habits. Nursing Times, 2014; 110(29): 12-14. 
Griffith R, Tengnah, C. Prescription of controlled drugs by non-medical prescribers. British Journal of Community Nursing, 2011; 16(11): 558.

Kinley J, Hancock D, Casterton J. Nurse prescribing in palliative care: putting training into practice. Nurse Prescribing. 2004; 2(2): 60-64.

Lafitte C, Etienne-Mastroianni B, Fournel, C, Natoli L, Foucaut AM, Girard N. Implementation of optimized supportive care and hospital needs along the management of patients with advanced lung cancer. Lung Cancer. 2018; 124: 143-147.

Latham K, Nyatanga B. Community palliative care clinical nurse specialists as independent prescribers: part 1. British Journal of Community Nursing. 2018a; 23(2): 94-98.

Latham K, Nyatanga B. Community palliative care clinical nurse specialists as independent prescribers: part 2. British Journal of Community Nursing. 2018b; 23(3): 126-133.

Lewis-Evans A, Jester R. Nurse prescribers' experiences of prescribing. Journal of Clinical Nursing. 2004; 13(7): 796-805.

Li H, Li J. Effectiveness of palliative care for non-small cell lung cancer (Review). Experimental and Therapeutic Medicine. 2016; 12(4): 2387-2389.

MacLure K, Johnston G, Diack L. Bond C, Cunningham S, Stewart D. Views of the Scottish general public on non-medical prescribing. International Journal of Clinical Pharmacy. 2013; 35(5): 704-710.

McPhillips D, Evans R, Ryan D, Daneshvav C, Sarker SA, Breen D. The role of a nurse specialist in a modern lung-cancer service. British Journal of Nursing (Oncology Supplement). 2015; 24(4): S21-S27. 
Mula C, Ware S. Extended independent prescribing in palliative care. Nursing Times. 2003; 99(18): 30-32.

National Cancer Action Team (NCAT). Quality in Nursing Excellence in cancer care: the contribution of the clinical nurse specialist 2010. https://www.macmillan.org.uk/documents/aboutus/commissioners/excellenceincancerc arethecontributionoftheclinicalnursespecialist.pdf (accessed 30 December 2019) National Institute of Clinical Excellence. Care of dying adults in the last days of life. 2015; Available from: https://www.nice.org.uk/guidance/ng31 (accessed 30 December 2019). Ngwenya N, Farquhar M, Ewing G. Sharing bad news of a lung cancer diagnosis: understanding through communication privacy management theory. Psycho-Oncology. $2015 ; 25(8):$ 913-918.

Noblet T, Marriott J, Graham-Clarke E, Rushton A. Barriers to and facilitators of independent non-medical prescribing in clinical practice: a mixed-methods review. Journal of Physiotherapy. 2017; 63(4): 221-234.

Nunn C. It's not just about pain: symptom management in palliative care. Nurse Prescribing. 2014; 12(7): 338-344.

Nursing and Midwifery Council (NMC). Realising professionalism: standards for education and training. Part 3: standards for prescribing programmes. 2018.

https://www.nmc.org.uk/globalassets/sitedocuments/education-standards/programmestandards-prescribing.pdf (accessed 2 January 2020) 
Nutall D, Rutt-Howard J. The Textbook of Non Medical Prescribing. 2011. file://C:/Users/sharon/Downloads/The\%20Textbook\%20of\%20Non-Medical\%20Prescribing.pdf (accessed 30 December 2019)

Royal College of Nursing (RCN). RCN factsheet on nurse prescribing in the UK, London: RCN; 2014.

Roy Castle Lung Cancer Foundation (RCLCF). Understanding the value of lung cancer nurse specialists. 2013.

http://documents.roycastle.org/UnderstandTheValueOfLungCancerNurseSpecialists V03 .$p d f$ (accessed 30 December 2019).

Royal Pharmaceutical Society. A competency framework for all prescribers, Great Britain: The Royal Pharmaceutical Society; 2016.

Ryan-Woolley, BM, McHugh GA, Luker KA. Prescribing by specialist nurses in cancer and palliative care: results of a national survey. Palliative Medicine. 2007; 21(4): 273-277.

Temel JS, Greer JA, Muzikansky A, Gallagher ER, Admane S, Jacson VA, Dahlin CM, Blinderman CD, Jacobson J, Pirl WF, Billings JA, Lynch TJ. Early palliative care for patients with metastatic non-small cell lung cancer. The New England Journal of Medicine.2010; 363(8): 733-742.

Tod AM, Redman J, McDonnell A, Borthwick D, White J. Lung cancer treatment rates and the role of the lung cancer nurse specialist: a qualitative study. BMJ Open. 2016; 5(12): 19.

Ward C. Clinical Nurse Specialist: The Unknown APRN. MEDSURG Nursing. 2018; 27(6): 347-348. 
Ward H, Armstrong A. Non-medical prescribing. In: Barton TD, Allan D. (1 $1^{\text {st }}$ ed.) Advanced Nursing Practice. London: Palgrave. 2015; p. 168-189.

Wong M, Lao XQ, Ho KF, Goggins WB, Tse S. Incidence and mortality of lung cancer: global trends and association with socioeconomic status. Scientific Reports. 2017; 7(1): 1-9.

Yount S, Beaumont J, Rosenbloom S, Cella D, Patel J, Hensing T, Jacobsen PB, Syrjala K, Abernethy AP. A brief symptom index for advanced lung cancer. Clinical Lung Cancer. 2012; 13(1): 14-23

Ziegler L, Bennett M, Blenkinsopp A, Coppock S. Non-medical prescribing in palliative care: a regional survey. Palliative Medicine. 2015; 29(2): 177-181. 